\title{
Study on Influencing Factors of Construction Accuracy of Cylinder Hydraulic Slip Forming Construction of Grain Silos
}

\author{
Hairong Huang, Menghua Lv, Guoran Hao \\ School of Civil Engineering, Henan University of Technology, Zhengzhou, Henan 450001, China.
}

How to cite this paper: Hairong Huang, Menghua Lv, Guoran Hao. (2022) Study on Influencing Factors of Construction Accuracy of Cylinder Hydraulic Slip Forming Construction of Grain Silos. Engineering Advances, 2(1), 80-87. DOI: 10.26855/ea.2022.06.007

Received: January 20, 2022

Accepted: February 14, 2022

Published: March 7, 2022

*Corresponding author: Menghua Lv, School of Civil Engineering, Henan University of Technology, Zhengzhou, Henan 450001, China.

Email: lmh731804728@qq.com

\begin{abstract}
Precision control is an important content to ensure the quality of cylinder hydraulic slip forming construction. There are many factors influencing it and there are very complicated relations among them. In order to clarify the hierarchical relationship and influence among the influencing factors, the factors influencing the construction accuracy of hydraulic slip forming were identified with the background of a new grain silo project in Henan province. The multi-layer recursive model of influencing factors was established with the method of ISM-MICMAC theory, and the weight ratio of each influencing factor was calculated by AHP. Finally, through the analysis of the important aspects to ensure the construction quality of the Grain Silo Wall hydraulic slipform, and the use of ISM-MICMAC and AHP to clarify the relationship between the influencing factors, found out the most important factors affecting the construction accuracy, it provides a certain reference for the successful completion of the construction of Silo Wall.
\end{abstract}

\section{Keywords}

Cylinder Slip Forming Construction, Construction Accuracy, Influencing Factors, ISM-MICMAC, AHP

\section{Research background and research problems}

Hydraulic slip forming construction during the process of the construction of the cylinder wall has the characteristic of fast construction speed and good construction structure integrity. However, due to its construction characteristics, the construction quality control of the construction is poor, and a series of serious quality problems such as working-deck central deviation, cylinder torsion and large vertical deviation of horizontal degree are not reversibility, which is easy to cause safety accidents [1]. Therefore, in the process of sliding up, in order to ensure the construction quality, the most important is to carry out precision control [2]. In the project, the so-called precision control is the construction deviation, component production deviation and other methods to control within the allowable deviation. For slip forming construction, accuracy control mainly includes of horizontal degree, verticality and torsion control [3]. How to control various construction deviations within the allowable deviation has always been a key point and difficulty.

The slip forming technics is difficult, and many factors will affect the construction accuracy. Without any attention, it is easy to cause deviation in the process of sliding up, and it is difficult and expensive to deal with the problems after the event. Under the restriction of this factor, it is particularly important to identify and comb the various influencing factors of affecting the construction accuracy of the slip forming work in advance. For the study of construction accuracy of sliding, China is mainly judged from the quality control method at present, and little attention is paid to the influencing factors of the accuracy and its relevance. In view of the deficiency of current research, this paper takes the 200,000 tons large diameter grain silo project in Henan province as an example, combining ISM-MICMAC and AHP methods to make the system more clear [4], and obtains the relationship between different influencing factors and the effect degree of different factors on the construction accuracy of grain silo hydraulic sliding form, so as to provide some 
reference value for the construction quality of other similar cylinder slip forming construction.

\section{Project Overview}

This project is a new 200,000 tons of large diameter grain shallow warehouse (cylinders) project, shallow warehouse inner diameter is $25 \mathrm{~m}$, cornice elevation is $28.5 \mathrm{~m}$, a total of 20 , a single warehouse capacity of 10,000 tons, the project area is located in the Yellow River alluvial plain, flat terrain, open terrain, with obvious transitional local climate characteristics of low hills and plain transition zone.

The main body of the shallow warehouse wall is reinforced concrete construction with 60 hoist frames, large tonnage jacks, and climbing rods are $\Phi 48.3 \times 3.5$ welded steel pipes. The warehouse wall is assembled with sliding from the elevation of- $0.300 \mathrm{~m}$ and slides to the end of the cornice with a sliding height of $28.80 \mathrm{~m}$.

\section{Identification of the factors affecting the construction accuracy of the Slip Forming Con- struction}

Through literature research and summary of similar problems and characteristics and experience exchange with professional slip forming work personnel, combined with the construction management practices of this grain cylinders project. According to the problems that are easy to occur in the process of construction, 11 common influencing factors are summarized from the three aspects of influencing factors of construction facilities, construction and construction environment (Table 1).

Table 1. Influencing factors of construction accuracy of hydraulic Slip Forming Construction of grain silos

\begin{tabular}{|c|c|c|c|}
\hline $\begin{array}{l}\text { Primary influen- } \\
\text { cing factors }\end{array}$ & No. & $\begin{array}{l}\text { Secondary influencing } \\
\text { factors }\end{array}$ & Factor description \\
\hline \multirow{4}{*}{$\begin{array}{l}\text { influencing } \\
\text { factors of con- } \\
\text { struction facili- } \\
\text { ties }\end{array}$} & $\mathrm{S} 1$ & $\begin{array}{l}\text { Climbing rods are } \\
\text { bending instability }\end{array}$ & $\begin{array}{l}\text { Climbing rods play a guiding role in the jacks climb, climbing rods bending instability part will } \\
\text { lead to part of the platform area cannot continue to slide, the shallow round warehouse using em- } \\
\text { bedded climbing rods, if the jacks oil leakage to the above, will have a greater impact on the con- } \\
\text { crete strength and the grip force between them, causing the jacks ball dirt jam, lead to the jacks } \\
\text { slide. }\end{array}$ \\
\hline & $\mathrm{S} 2$ & $\begin{array}{l}\text { The hydraulic jacks } \\
\text { rise are out of sync }\end{array}$ & $\begin{array}{l}\text { Jacks are the power source of the whole sliding system, the shallow round warehouse used jacks } \\
\text { quantity up to } 60 \text {, accumulation of stroke error, limiting adjustment may appear "back" phenome- } \\
\text { non lead to the pace of jacks are fast or slow, deviation leads to the jacks in sliding process can not } \\
\text { synchronous rise, make the various parts of the template system rise difference. }\end{array}$ \\
\hline & S3 & $\begin{array}{l}\text { Oil road is prone to } \\
\text { problems }\end{array}$ & $\begin{array}{l}\text { The shallow circular warehouse adopts graded and parallel oil road, with hydraulic oil entering } \\
\text { different jacks, and the oil road is prone to solid particulate matter pollution and causes uneven oil } \\
\text { supply of jacks. }\end{array}$ \\
\hline & $\mathrm{S} 4$ & $\begin{array}{l}\text { The operation platform } \\
\text { is weak in strength and } \\
\text { stiffness }\end{array}$ & $\begin{array}{l}\text { The substandard strength and stiffness of the operating platform is easy to reduce the effect of } \\
\text { adjusting the vertical degree of the silo and the center line, and because the hydraulic jacks are } \\
\text { extremely easy to produce cumulative errors, it will cause excessive deformation of the platform } \\
\text { and the surrounding rods. }\end{array}$ \\
\hline \multirow{3}{*}{$\begin{array}{l}\text { influencing } \\
\text { factors of con- } \\
\text { struction }\end{array}$} & S6 & $\begin{array}{l}\text { Concrete pouring is } \\
\text { prone to problems }\end{array}$ & $\begin{array}{l}\text { Sliding formwork construction has high requirements for the concrete technology. If the pouring is } \\
\text { uneven, it will lead to the uneven concrete outgoing molding strength, resulting in the uneven rub } \\
\text { resistance when the formwork rises. }\end{array}$ \\
\hline & S7 & $\begin{array}{l}\text { Errors occurred in the } \\
\text { monitoring of sliding } \\
\text { data }\end{array}$ & $\begin{array}{l}\text { During the construction of sliding, the horizontal degree and verticality should be monitored, and } \\
\text { the monitoring times should be large. If the observation is not timely, measurement methods or } \\
\text { environment have problems and so on will inevitably cause measurement data error. }\end{array}$ \\
\hline & S8 & $\begin{array}{l}\text { Slip forming equip- } \\
\text { ment installation is not } \\
\text { standard }\end{array}$ & $\begin{array}{l}\text { The assembly of the equipment only meet the standard is the premise to ensure the construction } \\
\text { accuracy, but in the actual construction process, due to the influence of various factors, the assem- } \\
\text { bly deviation exceeds the allowable deviation sometimes occurs, take template installation as an } \\
\text { example, the assembled template tilt single surface should be controlled at } 0.3 \% \text {, the structural } \\
\text { surface "wear skirt" phenomenon when exceeding the value. }\end{array}$ \\
\hline \multirow{3}{*}{$\begin{array}{l}\text { influencing } \\
\text { factors of con- } \\
\text { struction envi- } \\
\quad \text { ronment }\end{array}$} & S9 & $\begin{array}{l}\text { sunshine causes the } \\
\text { temperature difference } \\
\text { between the sunny side } \\
\text { and the shady side }\end{array}$ & $\begin{array}{l}\text { During the sliding, the strength of the concrete exposed by the sun is significantly higher than on } \\
\text { the other side, and the resistance of the formwork during the sliding process will be greater, caus- } \\
\text { ing the template to twist in one direction. }\end{array}$ \\
\hline & S10 & $\begin{array}{l}\text { The external tempera- } \\
\text { ture is too high or too } \\
\text { low }\end{array}$ & $\begin{array}{l}\text { The external temperature will have a direct impact on the concrete condensation time. The shallow } \\
\text { silo construction time coincides with the summer, when the temperature is very high, the construc- } \\
\text { tion continuity is not good and the concrete cracking risk is high; In addition, when the temperature } \\
\text { is too low, the concrete temperature is low and strength is insufficient. }\end{array}$ \\
\hline & S11 & $\begin{array}{l}\text { Instantaneous wind } \\
\text { and wind direction } \\
\text { change }\end{array}$ & $\begin{array}{l}\text { In the windy season or affected by the instantaneous wind, the silo will produce corresponding } \\
\text { displacement changes, resulting in platform offset, making the Climbing rods affected by the def- } \\
\text { lection stress, and reduce the bearing capacity. }\end{array}$ \\
\hline
\end{tabular}




\section{Hierarchical analysis based on the factors affecting the ISM}

ISM (Interpretation Structure Model) interpretation structural model is an analysis method in modern system engineering. It can regionalize and hierarchical decompose the messy and complex relationships between elements through the construction matrix, and then obtain a clear multi-level recurrence structure model between the whole system, so as to improve the understanding and of the whole system [5]. The cross-influence matrix multiplication (MICMAC) can understand the driving forces and dependencies of the different factors based on the ISM. Therefore, combining the two methods to analyze the correlation between the factors affecting the construction accuracy of the silo hydraulic slip forming work can clarify the internal hierarchy of the system.

\subsection{The set of influencing factors}

Based on the understanding of the ISM theory, the above influence factors are numbered. Select the 11 ( $n=11)$ factors affecting the construction accuracy of the slip forming work (S1, S2, .., S11) and a set of influencing factors of construction accuracy of silo wall called $\mathrm{S}$ is established:

$$
S=\{S 1, S 2, \ldots, S 11 \mid 2 \leq n \leq 11\}
$$

\subsection{Establish the adjacency matrix}

In order to digitize the relationship between the factors affecting of the construction accuracy of slip forming construction. Adjacency matrix A was used to represent whether there are direct influence relationships $\mathrm{R}$ between any two factors $(S i, S j)$. When there is a direct influence relationship, remember as $\operatorname{SiRSj}$, right now $a_{i j}=1$; when there is no direct influence relationship, remember as $S i \bar{R} S j$, right now $a_{i j}=0$ :

$$
a_{i j}= \begin{cases}1, & S i R S j \\ 0, & S i \bar{R} S j\end{cases}
$$

In this case, $S i$ is the row, $S j$ is the column. Then the established adjacency matrix A is:

$$
A=\left[\begin{array}{lllllllllll}
0 & 1 & 0 & 0 & 0 & 0 & 0 & 0 & 0 & 0 & 0 \\
1 & 0 & 0 & 0 & 0 & 0 & 0 & 1 & 0 & 0 & 0 \\
0 & 1 & 0 & 0 & 1 & 0 & 0 & 1 & 0 & 0 & 0 \\
1 & 0 & 0 & 0 & 0 & 0 & 0 & 0 & 0 & 0 & 0 \\
0 & 1 & 0 & 0 & 0 & 0 & 0 & 0 & 0 & 0 & 0 \\
0 & 0 & 0 & 0 & 0 & 0 & 0 & 0 & 1 & 0 & 0 \\
0 & 1 & 0 & 0 & 0 & 0 & 0 & 0 & 0 & 0 & 0 \\
1 & 1 & 0 & 1 & 0 & 0 & 0 & 0 & 0 & 0 & 0 \\
1 & 0 & 0 & 0 & 0 & 0 & 0 & 0 & 0 & 0 & 0 \\
0 & 0 & 0 & 0 & 0 & 1 & 0 & 0 & 0 & 0 & 0 \\
1 & 1 & 0 & 0 & 0 & 0 & 0 & 0 & 0 & 0 & 0
\end{array}\right]
$$

\subsection{Establish the accessible matrix}

In the ISM model, the influence relationship among the factors is transitive. During the exploration of this influencing factor, this transmission relationship indicates an indirect relationship between the factors, i.e.:

$$
\left.\begin{array}{l}
\text { SiRSj } \\
\text { SjRSk }
\end{array}\right\} \Rightarrow \text { SiRSk }
$$

To indicate whether there is such an indirect relationship from one influencing factor to another, it can be represented by an accessible matrix and when there is a path with the maximum length of $\mathrm{r}$ from $\mathrm{i}$ to $\mathrm{j}, m_{i j}=1$; vice versa is zero. According to the Boolean algebra operation rule we can solve the accessible matrix M: 


$$
(A+I) \neq(A+I)^{2} \neq \ldots \neq(A+I)^{r}(A+I)^{r+1}=\ldots=(A+I)^{n}
$$

In this formulation, I represent the unit matrix of equal order to the adjacency matrix, and represents the maximum number of transitions under the loop-less condition.

Then the accessible matrix M calculated by MATLAB software is:

$$
M=\left[\begin{array}{lllllllllll}
1 & 1 & 0 & 1 & 0 & 0 & 0 & 1 & 0 & 0 & 0 \\
1 & 1 & 0 & 1 & 0 & 0 & 0 & 1 & 0 & 0 & 0 \\
1 & 1 & 1 & 1 & 1 & 0 & 0 & 1 & 0 & 0 & 0 \\
1 & 1 & 0 & 1 & 0 & 0 & 0 & 1 & 0 & 0 & 0 \\
1 & 1 & 0 & 1 & 1 & 0 & 0 & 1 & 0 & 0 & 0 \\
1 & 1 & 0 & 1 & 0 & 1 & 0 & 1 & 1 & 0 & 0 \\
1 & 1 & 0 & 1 & 0 & 0 & 1 & 1 & 0 & 0 & 0 \\
1 & 1 & 0 & 1 & 0 & 0 & 0 & 1 & 0 & 0 & 0 \\
1 & 1 & 0 & 1 & 0 & 0 & 0 & 1 & 1 & 0 & 0 \\
1 & 1 & 0 & 1 & 0 & 1 & 0 & 1 & 1 & 1 & 0 \\
1 & 1 & 0 & 1 & 0 & 0 & 0 & 1 & 0 & 0 & 1
\end{array}\right]
$$

\subsection{Build the ISM model}

Region and hierarchy of accessible matrix can make model building more scientific. The set $\mathrm{S}$ of the factors affecting of the construction accuracy of slip forming construction of grain silos is divided according to reachable set R(Si), antecedent set $\mathrm{A}(\mathrm{Si})$, common set $\mathrm{C}(\mathrm{Si})$,beginning set $\mathrm{B}(\mathrm{Si})$, and ending set $\mathrm{E}(\mathrm{Si})$ and decomposed by the accessible matrix M. That is, Table 2:

Table 2. Regional division table

\begin{tabular}{cccccc}
\hline $\mathrm{Si}$ & $\mathrm{A}(\mathrm{Si})$ & $\mathrm{R}(\mathrm{Si})$ & $\mathrm{C}(\mathrm{Si})$ & $\mathrm{B}(\mathrm{Si})$ & $\mathrm{E}(\mathrm{Si})$ \\
\hline 1 & $1,2,3,4,5,6,7,8,9,10,11$ & $1,2,4,8$ & $1,2,4,8$ & & 1 \\
2 & $1,2,3,4,5,6,7,8,9,10,11$ & $1,2,4,8$ & $1,2,4,8$ & & 2 \\
3 & 3 & $1,2,3,4,5,8$ & 3 & 3 & \\
4 & $1,2,3,4,5,6,7,8,9,10,11$ & $1,2,4,8$ & $1,2,4,8$ & & 4 \\
5 & 3,5 & $1,2,4,5,8$ & 5 & & 8 \\
6 & 6,10 & $1,2,4,6,8,9$ & 6 & & \\
7 & 7 & $1,2,4,7,8$ & 7 & 7 & \\
8 & $1,2,3,4,5,6,7,8,9,10,11$ & $1,2,4,8$ & $1,2,4,8$ & & \\
9 & $6,9,10$ & $1,2,4,8,9$ & 9 & & \\
10 & 10 & $1,2,4,6,8,9,10$ & 10 & & \\
11 & 11 & $1,2,4,8,11$ & 11 & 11 & \\
\hline
\end{tabular}

The analysis shows that the factors belong to the same region $\mathrm{P}$, which means that this accessibility matrix is inseparable. After the regional division, it is necessary to determine the hierarchy of the elements within the region. The $M$ was graded according to the basic method, where the $L_{0}=\varphi, L_{1}=P-L_{0}, L_{2}=P-L_{0}-L_{1}, L_{3}=P-L_{0}-L_{1}-L_{3}$, $L_{4}=P-L_{0}-L_{1}-L_{2}-L_{3}$. After calculation, the hierarchical classification of this region is:

$$
\Pi(P)=L_{1}, L_{2}, L_{3}, L_{4}=\{S 1, S 2, S 4, S 8\},\{S 5, S 7, S 9, S 11\},\{S 3, S 6\},\{S 10\}
$$

The ISM model was established based on the rank division and the adjacency matrix, as shown in Figure 1.

\subsection{Build the ISM-MICMAC model}

By using the reachable matrix $\mathrm{M}$ to draw the driving force-dependence distribution diagram of the factors affecting the construction accuracy of the silo hydraulic slip forming work, the position of each influencing factor in ISM can be 
clearly defined. Specifically, the sum of the horizontal axis in the matrix $M$ indicates the size of the driving force of the line factor, and the sum of the vertical axis indicates the dependence size of the column factor [6]. Thus, the driving force-dependence matrix of the system is obtained in Figure 2.

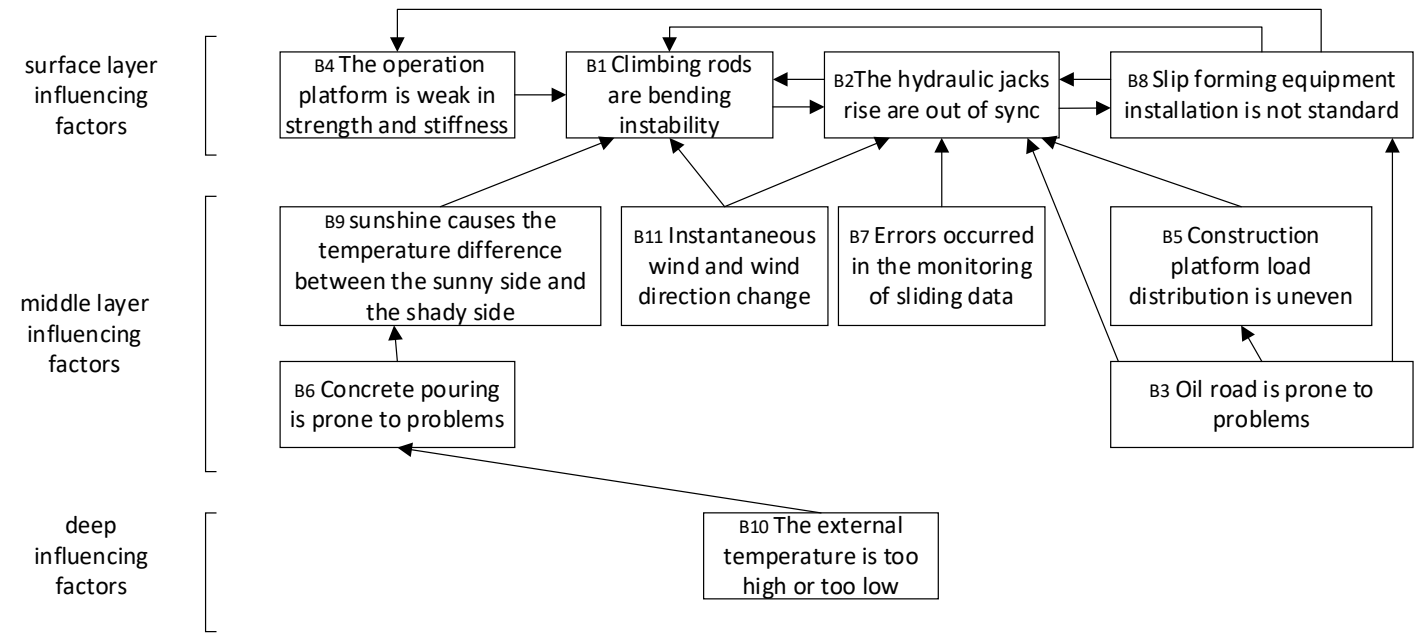

Figure 1. ISM model of Influencing factors of construction accuracy of cylinder hydraulic slip forming construction of grain silos.

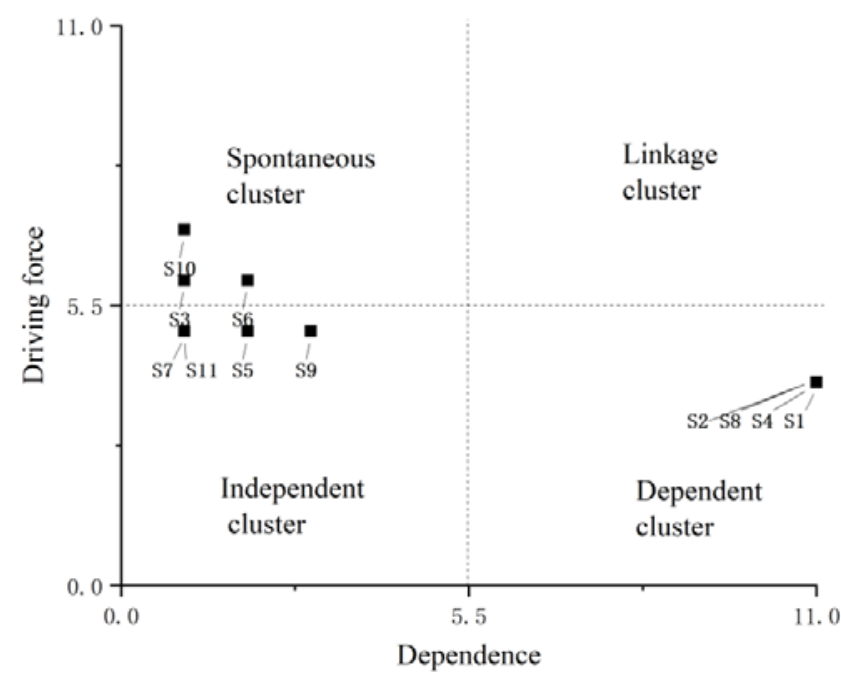

Figure 2. The driving force- dependence distribution diagram of the factors affecting the construction accuracy of the silo hydraulic slip forming work.

\subsection{Analysis of the model}

It can be seen from the ISM model that the establishment of the model makes the complex relationship between the influencing factors more organized and hierarchical. According to Figure 1, level 4 influencing factors are divided into surface layer influencing factors, middle layer influencing factors and deep influencing factors:

(1) Surface influence factors are the most intuitive impact on the construction accuracy of hydraulic slip forming of grain silo. Ensuring the strength and stiffness of the operation platform, preventing the instability of the climbing rods during sliding, making the synchronous slide rise of the jacks and ensuring the accuracy of the slip forming equipment assembly are highly dependent on other influencing factors, and are easily affected by other factors. Among them, many other factors are easy to cause the bending instability of the climbing rods and the hydraulic jack rise asynchronization, which are the most direct factor affecting the construction accuracy of slip forming construction.

(2) The influencing factors of the middle layer and the deep layer are the root causes of the construction accuracy. 
The interaction of various objective factors such as uneven load layout of operation platform, problems in concrete pouring, and uncomfortable external temperature lead to the surface influencing factors, and finally the joint action lead to the deviation of sliding in the construction process. Among them, the external temperature is characterized by high driving force and low dependence, which shows that the temperature will have a deep impact on the construction accuracy of the sliding work, but it is not easily affected by other factors.

\section{Analysis of the influence degree based on the factors affecting AHP}

Above, the ISM MICMAC model was used to conduct quantitative analysis on the factors affecting the construction accuracy of hydraulic sliding work of grain silos, and different influencing factors were established into a structural system with a clear relationship. Next, AHP (Analytic Hierarchy Process) is used to further quantitative analysis of the influencing factors, which can obtain the weight ratio of the influence degree of different influencing factors on the construction accuracy of sliding mode in the actual engineering, and master the key factors affecting the construction accuracy. The main analysis steps are: construct the judgment matrix between the factors in the established evaluation index system and calculate the weight, and finally analyze the influencing factors through the weight size [7].

\subsection{Establish an evaluation index system}

The influencing factor system of construction accuracy of cylinder hydraulic slip forming construction of grain silos (U) is directly established from Table 1, which contains first-order influencing factors (A) and second-order influencing factors (B), as shown in Table 3.

Table 3. The influencing factor system of construction accuracy of cylinder hydraulic slip forming construction of grain si$\operatorname{los}(\mathbf{U})$

\begin{tabular}{|c|c|c|}
\hline \multirow{11}{*}{$\begin{array}{l}\text { system of construction accuracy } \\
\text { of cylinder hydraulic slip forming } \\
\text { construction of grain silos (U) }\end{array}$} & \multirow{4}{*}{$\begin{array}{l}\text { A1 1influencing factors of } \\
\text { construction facilities }\end{array}$} & B1 Climbing rods are bending instability \\
\hline & & B2 The hydraulic jacks rise are out of sync \\
\hline & & B3 Oil road is prone to problems \\
\hline & & B4 The operation platform is weak in strength and stiffness \\
\hline & \multirow{4}{*}{$\begin{array}{l}\text { A2 influencing factors of } \\
\text { construction }\end{array}$} & B5 construction platform load distribution is uneven \\
\hline & & B6 Concrete pouring is prone to problems \\
\hline & & B7 Errors occurred in the monitoring of sliding data \\
\hline & & B8 Slip forming equipment installation is not standard \\
\hline & \multirow{3}{*}{$\begin{array}{l}\text { A3 influencing factors of } \\
\text { construction environment }\end{array}$} & $\begin{array}{l}\text { B9 sunshine causes the temperature difference between the } \\
\text { sunny side and the shady side }\end{array}$ \\
\hline & & B10 The external temperature is too high or too low \\
\hline & & B11 Instantaneous wind and wind direction change \\
\hline
\end{tabular}

\subsection{Calculation of index weight}

According to the 1-9 scaling method, the expert scoring method is used to issue questionnaires to the construction management personnel of the shallow round warehouse, experts with rich theoretical and practical experience in granary construction, and college teachers, score the constructed judgment matrix, and finally obtained 5 valid questionnaire forms.

For the recovered questionnaires, the relative weights of all the elements in the judgment matrix constructed in the questionnaire were first calculated separately using geometric averaging. However, the judgment matrix obtained by comparing the pairwise factors is not necessarily reasonable, but it also needs to test whether the judgment matrix is consistent based on formula $C R=\frac{C I}{R I}$ and $C I=\frac{\lambda_{\max }-n}{n-1}$. When $C R<0.1$, this judgment matrix is considered to meet the consistency requirements [8]. After testing, the calculated judgment matrices all meet the consistency requirements.

Finally, by calculating the judgment matrix of each expert separately, the weight data obtained from each questionnaire was assembled, and then the geometric average method was used to take the mean of the calculated weight as the final result. The comprehensive weights of the final influencing factors are shown in Table 3.

According to Table 3, the weight of the first-level influencing factors in this system is around 0.3, among which the weight of construction facilities accounts for the largest proportion of 0.4039 . Among the secondary influencing factors, asynchronization rise of hydraulic jacks and high or low external temperature are the most important factors affecting 
the construction accuracy, with the weight of 0.1649 and 0.1427 respectively. It can be seen that in the construction process, the importance of ensuring the synchronous rise of the sliding device and ensuring the continuity, operation and construction quality in the extreme temperature situation. Other influencing factors such as improper layout of the oil road, monitoring error of slip forming data and uneven load layout of the construction platform, the importance of management and human factors have a great impact on them. The slip forming construction site follows the "three points of sliding, seven in charge", and improving the level of construction management can effectively ensure the construction accuracy of the sliding work.

Table 4. Index weights of influencing factors

\begin{tabular}{|c|c|c|c|c|c|}
\hline \multirow{12}{*}{$\begin{array}{l}\text { The influencing factor system of } \\
\text { construction accuracy of cylinder } \\
\text { hydraulic slip forming construction } \\
\text { of grain silos(U) }\end{array}$} & $\begin{array}{l}\text { first-level influencing } \\
\text { factors (A) }\end{array}$ & $\begin{array}{l}\text { average } \\
\text { weight }\end{array}$ & $\begin{array}{l}\text { second-level influencing fac- } \\
\text { tors (B) }\end{array}$ & $\begin{array}{l}\text { average } \\
\text { weight }\end{array}$ & $\begin{array}{l}\text { The } \\
\text { sorting }\end{array}$ \\
\hline & \multirow{4}{*}{$\begin{array}{l}\text { A1 1influencing } \\
\text { factors of construc- } \\
\text { tion facilities }\end{array}$} & \multirow{4}{*}{0.4039} & $\begin{array}{l}\text { B1 Climbing rods are bend- } \\
\text { ing instability }\end{array}$ & 0.0832 & 3 \\
\hline & & & $\begin{array}{l}\text { B2 The hydraulic jacks rise } \\
\text { are out of sync }\end{array}$ & 0.1649 & 1 \\
\hline & & & $\begin{array}{l}\text { B3 Oil road is prone to prob- } \\
\text { lems }\end{array}$ & 0.0764 & 7 \\
\hline & & & $\begin{array}{l}\text { B4 The operation platform is } \\
\text { weak in strength and stiffness }\end{array}$ & 0.0784 & 6 \\
\hline & \multirow{4}{*}{$\begin{array}{l}\text { A2 influencing } \\
\text { factors of construc- } \\
\text { tion }\end{array}$} & \multirow{4}{*}{0.3034} & $\begin{array}{l}\text { B5 construction platform load } \\
\text { distribution is uneven }\end{array}$ & 0.0998 & 3 \\
\hline & & & $\begin{array}{l}\text { B6 Concrete pouring is prone } \\
\text { to problems }\end{array}$ & 0.0634 & 9 \\
\hline & & & $\begin{array}{l}\text { B7 Errors occurred in the } \\
\text { monitoring of sliding data }\end{array}$ & 0.0808 & 5 \\
\hline & & & $\begin{array}{l}\text { B8 Slip forming equipment } \\
\text { installation is not standard }\end{array}$ & 0.0832 & 4 \\
\hline & \multirow{3}{*}{$\begin{array}{l}\text { A3 influencing } \\
\text { factors of construc- } \\
\text { tion environment }\end{array}$} & \multirow{3}{*}{0.2927} & $\begin{array}{l}\text { B9 sunshine causes the tem- } \\
\text { perature difference between the } \\
\text { cunnw cido and tho chadv cido }\end{array}$ & 0.0693 & 8 \\
\hline & & & $\begin{array}{l}\text { B10 The external temperature } \\
\text { is too high or too low }\end{array}$ & 0.1427 & 2 \\
\hline & & & $\begin{array}{l}\text { B11 Instantaneous wind and } \\
\text { wind direction change }\end{array}$ & 0.0579 & 10 \\
\hline
\end{tabular}

\section{Conclusion}

In this paper, ISM-MICMAC and AHP method are used creatively to provide a new idea for studying the factors affecting the construction accuracy of silo hydraulic of slip forming construction: The application of the ISM-MICMAC model analyzes the factors affecting the construction accuracy from a qualitative point of view, and intuitively shows the logical relationship between the various factors through the form of explaining the structural model; Determine the weight value of each factor in the construction system by using AHP quantitative analysis, and obtain the relative importance of complex factors. Studies have shown:

(1) The method of system engineering is applied to divide the location division and level division of slip forming construction, and finally the four-level hierarchical structure model is established, so that the logical relationship between the influencing factors of slip forming construction accuracy can be expressed intuitively.ISM Combined with MICMAC model, it can be seen that the operation platform has not enough strength and appropriate stiffness, climbing rods bending instability, hydraulic jacks rise dissynchronization and irregular sliding device assembly are the most intuitive manifestations of poor precision control in the slip forming construction process.

(2) From each factors weight size, hydraulic jack rise dissynchronization and external temperature is too high or too low are the most important factor affecting the construction accuracy, shows that for the shallow round sliding work related personnel and practitioners, both factors affect the construction accuracy of extremely important factors, should focus in the construction process.

(3) The specialty of slip forming construction is strong. Not all conventional construction teams can adapt to the con- 
tinuous operation of slip forming construction and ensure the quality of construction accuracy, so there are more stringent requirements for the professionalism of the construction team and the management of the construction team and the self-control consciousness of operation quality. Therefore, we should improve the professional awareness of the construction labor team, do a good job of relevant training and education, improve the operation ability, staff arrangement to ensure the appropriate amount of tasks, fixed post, problems layer by layer decomposition responsibility, implementation to people, management personnel to do a good job of comprehensive coordination, to make high quality granary sliding work.

\section{References}

[1] Peng, X. C. (2020). Guide to understanding and application of engineering technical standards for sliding formwork [M]. Beijing. China Building Industry Press, 2020.

[2] Zhao, P. (2019). The precision control of sliding form construction and the treatment of common problems are discussed [J]. Construction Materials \& Decoration, 2019, 571(10): 27-28.

[3] Nie, C. M. (2011). Handbook of Prevention and Control of Common Defects in construction engineering quality [M]. Beijing: China Building Industry Press, 2011.

[4] Du, D., Pang, Q. H.,Wu, Y. (2015). Modern comprehensive evaluation method and case selection [M]. 3rd edition. Beijing: Tsinghua University Press, 2015.

[5] Huang, W., Zhang, L. M., et al. (2014). Analysis on quality influencing factors of the rammed-earth wall based on an interpretative structural model [J]. Journal of Xi'an University of Architecture \& Technology (Natural Science Edition), 2014, 46(3): 333-341.

[6] Zhao, H. R., Jiang, H. J., Guo, S. (2015). Research on Forewarning Index System for Management of Grid Corporations Based on ISM and MICMAC Model [J]. Shanxi Electric Power, 2015, 43(3): 11-15.

[7] Gao, X. Q., Chen, W., Zhao, Z. R. (2018). Application of AHP Based on Expert Group Decision in PPP Project Risk Management [J]. Construction Technology, 2018, 47(S1): 985-988.

[8] Yang, Z. Z., Fan, Y. Y. (2018). Risk Analysis on the Girder of Cable-Stayed Bridges at the Construction Phase: A Study Based on ISM and AHP [J]. Journal of Engineering Management, 2018, 32(3): 124-128. 